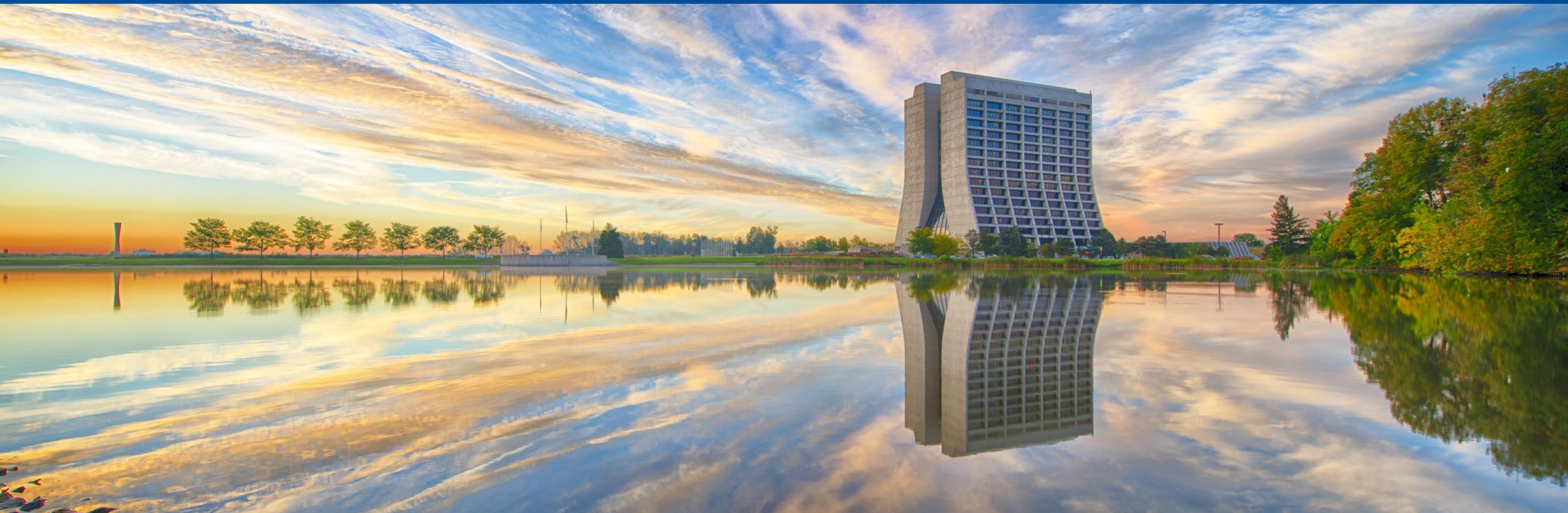

\title{
Status of FNAL and the PIP-II project
}

Lia Merminga

$3^{\text {rd }}$ J-PARC Symposium

September 23-26, 2019

Tsukuba, Japan
In partnership with:

India/DAE

Italy/INFN

UK/STFC

France/CEA/Irfu, CNRS/IN2P3

This document was prepared by [PIP-II Collaboration] using the resources of the Fermi National Accelerator Laboratory (Fermilab), a U.S. Department of Energy, Office of Scienc $\mathbf{P} / \mathbf{F}_{-} / \boldsymbol{H}_{\text {ser }}$ Facility. Fermilab is managed by Fermi Research Alliance, LLC (FRA), acting under Contract No. DE-AC02-07CH11359.

$B P=11$ 


\section{Outline}

- Fermilab at a Glance

- LBNF/DUNE/PIP-II: Context and Science Objectives

- PIP-II Project Overview

- International Partnerships

- Summary 


\section{Fermilab at a Glance}

- America s particle physics and accelerator laboratory $=$

- $\sim 1,800$ staff at $\$ 550 \mathrm{M} / \mathrm{yr}$

- 6,800 acres of federal land

- 4,000 scientists from $>50$ countries use Fermilab facilities

As we move into the next 50 years, our vision remains to solve the mysteries of matter, energy, space, and time for the benefit of all.

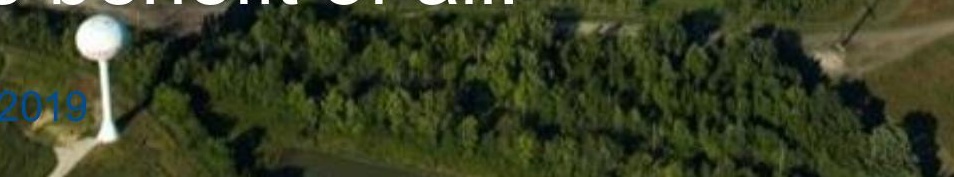


Fermilab accelerator complex:

\section{operating at $>750 \mathrm{~kW}$ now}

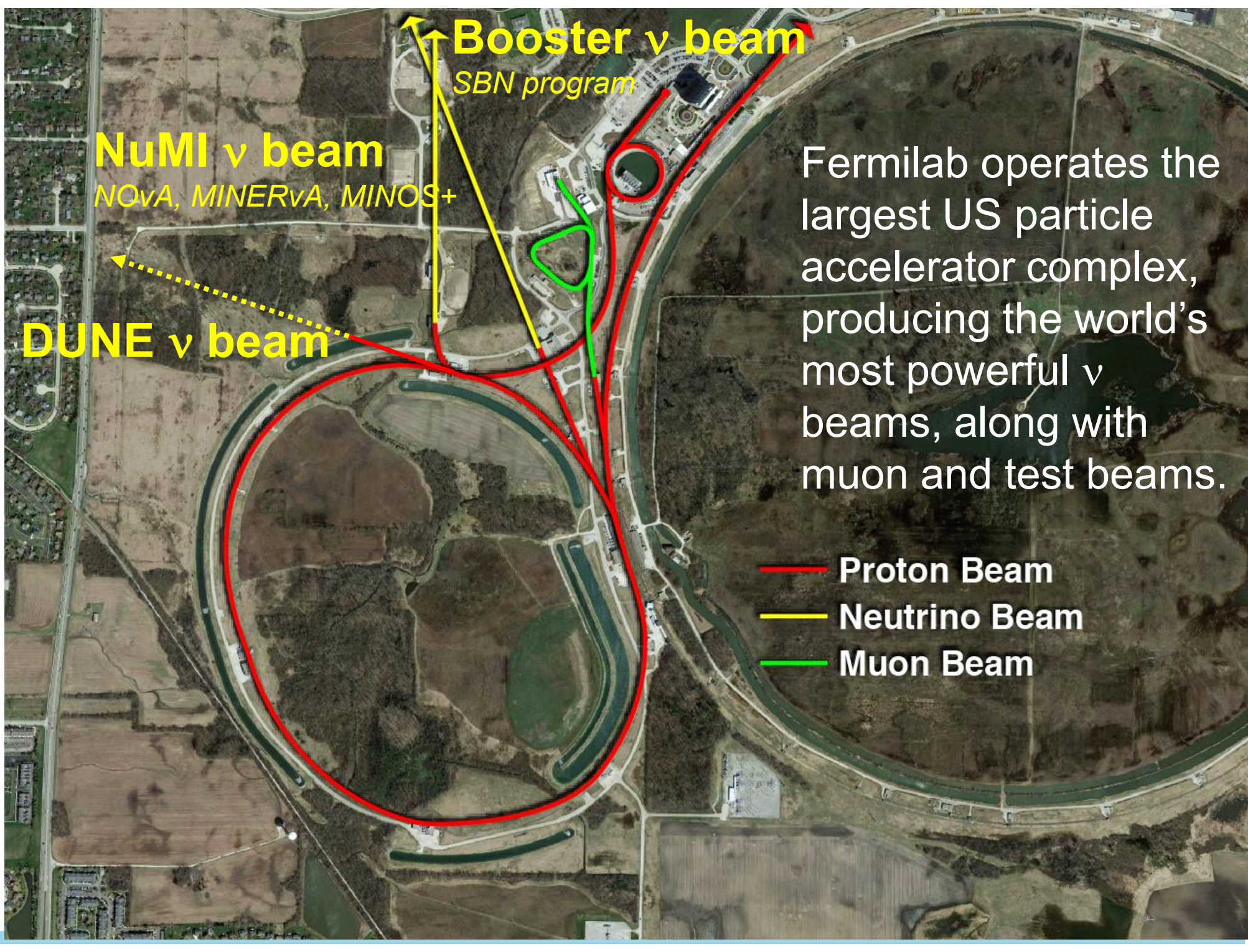




\section{Neutrinos to Minnesota...generation $2 \rightarrow 3$ (DUNE)}

\section{NOvA...our present flagship neutrino experiment}

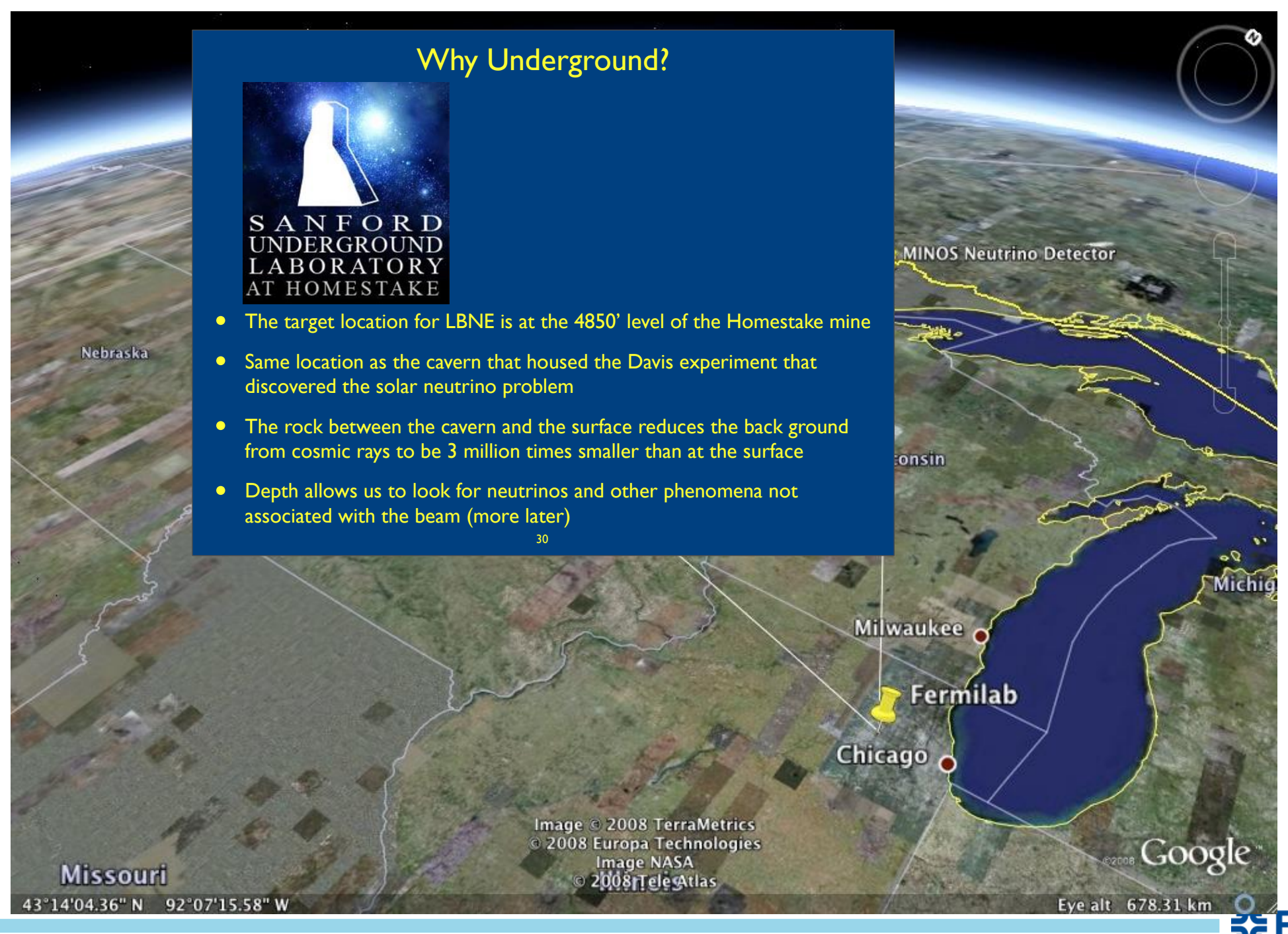




\section{Accelerator operations....excellent}

- World record performance in proton beam power for neutrinos achieved - 754 kW

- Record was broken three weeks in a row in January.

- New targets and booster improvements needed to go higher and ensure readiness for PIP-II

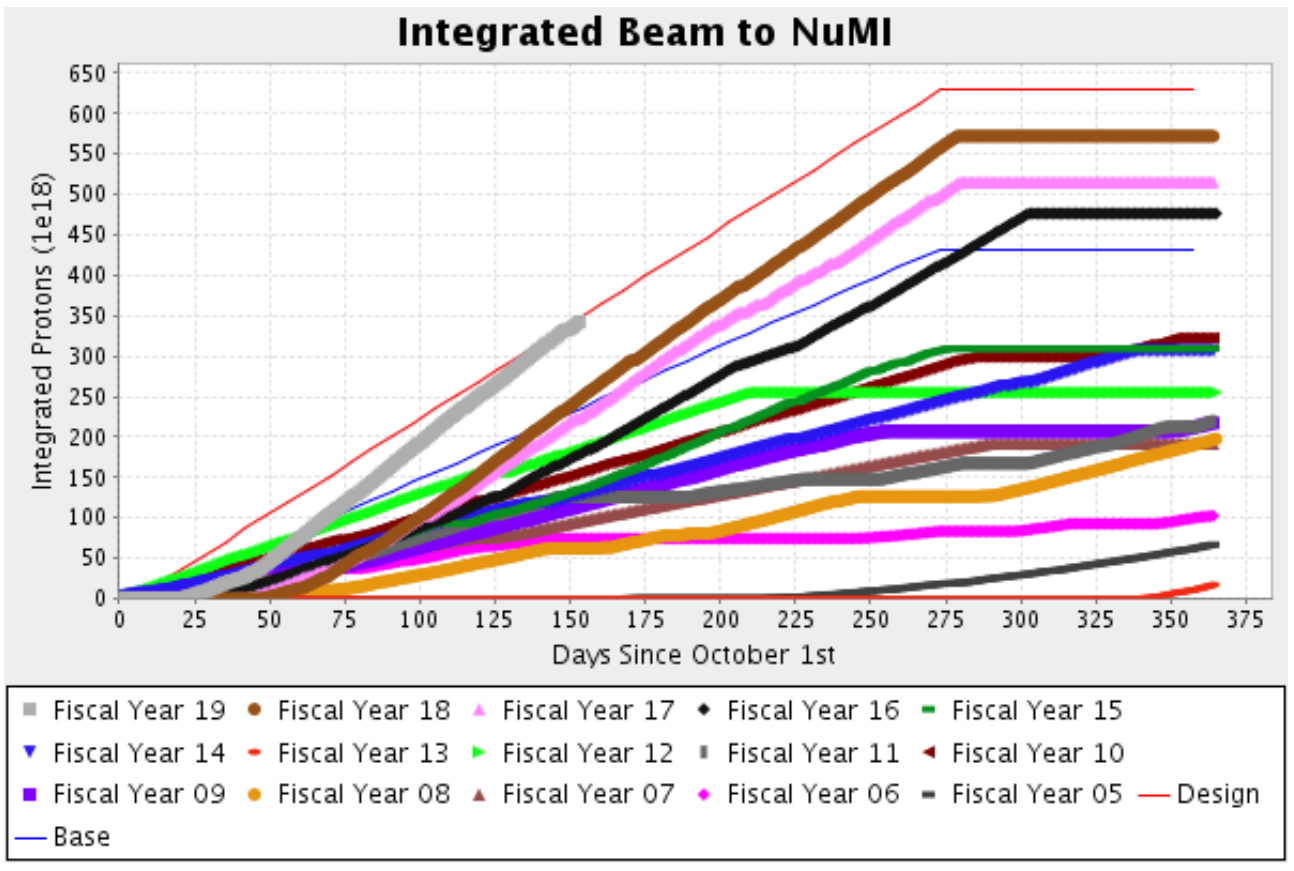




\section{P5 Report}

"The U.S. is well positioned to host a world leading neutrino physics program. Its centerpiece would be a next generation long-baseline neutrino facility (LBNF)."

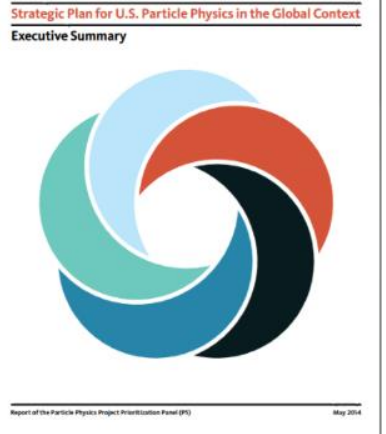

Recommendation 13: Form a new international collaboration to design and execute a highly capable Long-Baseline Neutrino Facility (LBNF) hosted by the U.S. To proceed, a project plan and identified resources must exist to meet the minimum requirements in the text. LBNF is the highest priority large project in its timeframe.

"LBNF would combine a high-intensity neutrino beam and a large-volume precision detector sited underground a long distance away to make accurate measurements of the oscillated neutrino properties, ... search for proton decay and neutrinos from supernova bursts. A powerful, wideband neutrino beam would be realized with Fermilab's PIP-II upgrade project, which provides very high intensities in the Fermilab accelerator complex."

Recommendation 14: Upgrade the Fermilab proton accelerator complex to produce higher intensity beams. R\&D for the Proton Improvement Plan II (PIP-II) should proceed immediately, followed by construction, to provide proton beams of $>1 \mathrm{MW}$ by the time of first operation of the new long-baseline neutrino facility. 


\section{PIP-II / LBNF / DUNE}

- Powerful proton beams (PIP-II)

- 1.2 MW upgradable to multi-MW (2.4 MW Phase 2) to enable world's most intense neutrino beam with wideband capability

- Dual-site detector facilities (LBNF)

- Deep underground cavern (1.5 km) of 70kt liquid argon fiducial volume

- A long baseline (1300 km)

- Deep Underground Neutrino Experiment (DUNE)

- Liquid Argon - the next-generation neutrino detector

\section{$1300 \mathrm{~km}$}

South Dakota sanford

Underground

Research

Facility

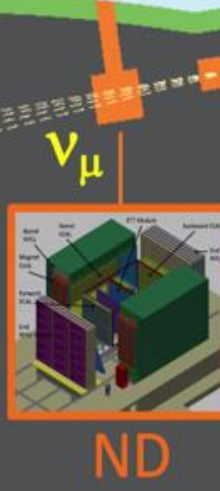

ND

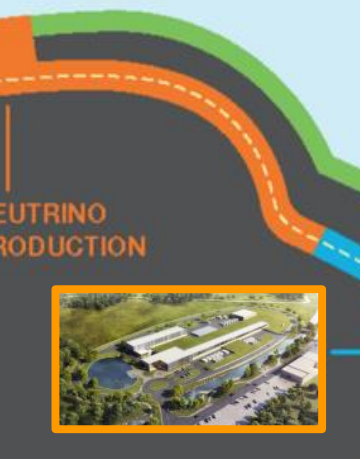

PIP-II
Chicago

Fermilab 


\section{PUNE Science Objectives}

Neutrinos - most ubiquitous matter particle in the universe, yet the least understood. Opportunities for game changing physics discoveries:

- Origin of matter Investigate leptonic CP violation, mass hierarchy, and precision oscillation physics

$>$ Discover what happened after the big bang: Are neutrinos the reason the universe is made of matter?

- Neutron Star and Black hole formation

Ability to observe supernovae events

$>$ Use neutrinos to look into the cosmos and watch the formation of neutron stars and black holes in real time

- Unification of forces

Investigate nucleon decay targeting SUSY-favored modes

$>$ Move closer to realizing Einstein's dream of a unified theory of matter and energy 


\section{PIP-II....a new accelerator to generate neutrinos}

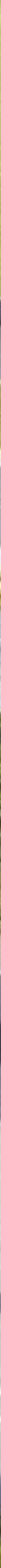




\section{P5 Report defines PIP-II Mission}

PIP-Il will enable the world's most intense beam of neutrinos to the international LBNF/DUNE project, and a broad physics research program, powering new discoveries for decades to come.

\section{PIP-II linac will provide:}

\section{Beam Power}

$>$ Meeting the needs for the start of DUNE (1.2 MW proton beam)

$>$ Upgradeable to multi-MW capability

\section{Flexibility}

$>$ Compatible with $\mathrm{CW}$-operations which greatly increases the linac output

$>$ Customized beams for specific science needs

$>$ High-power beam to multiple users simultaneously

\section{Reliability}

$>$ Fully modernizing the front-end of the Fermilab accelerator complex 


\section{PIP-II Scope Overview}

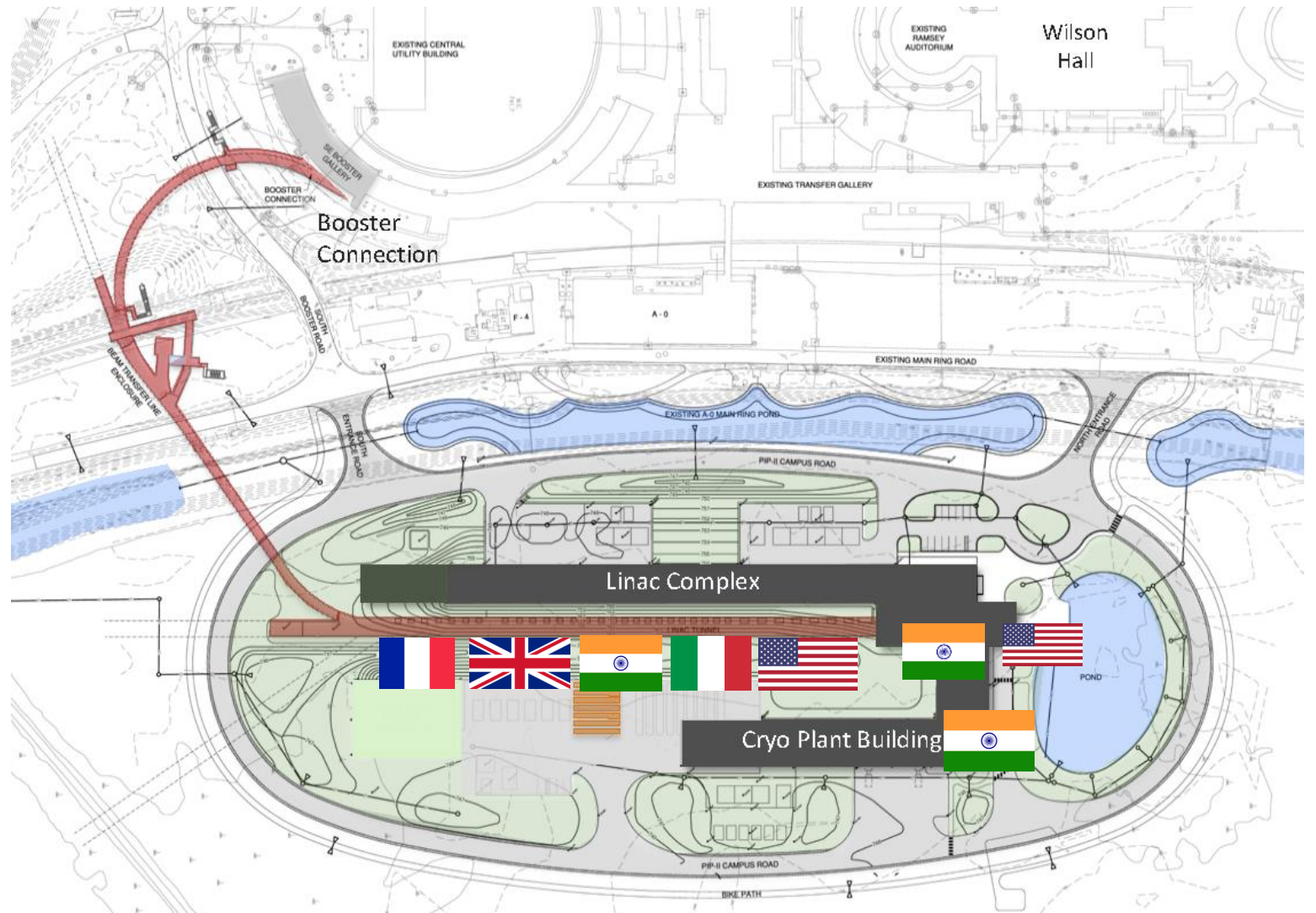

The PIP-II scope enables the accelerator complex to reach 1.2 MW proton beam on LBNF target.
$800 \mathrm{MeV} \mathrm{H}-$ linac

- Warm Front End

- SRF section

Linac-to-Booster transfer line

- 3-way beam split

Upgraded Booster

- $20 \mathrm{~Hz}, 800 \mathrm{MeV}$ injection

- New injection area Upgraded Recycler \& Main Injector

- RF in both rings Conventional facilities

- Site preparation

- Cryoplant Building

- Linac Complex

- Booster Connection ฟFermilab 


\section{PIP-II Site}

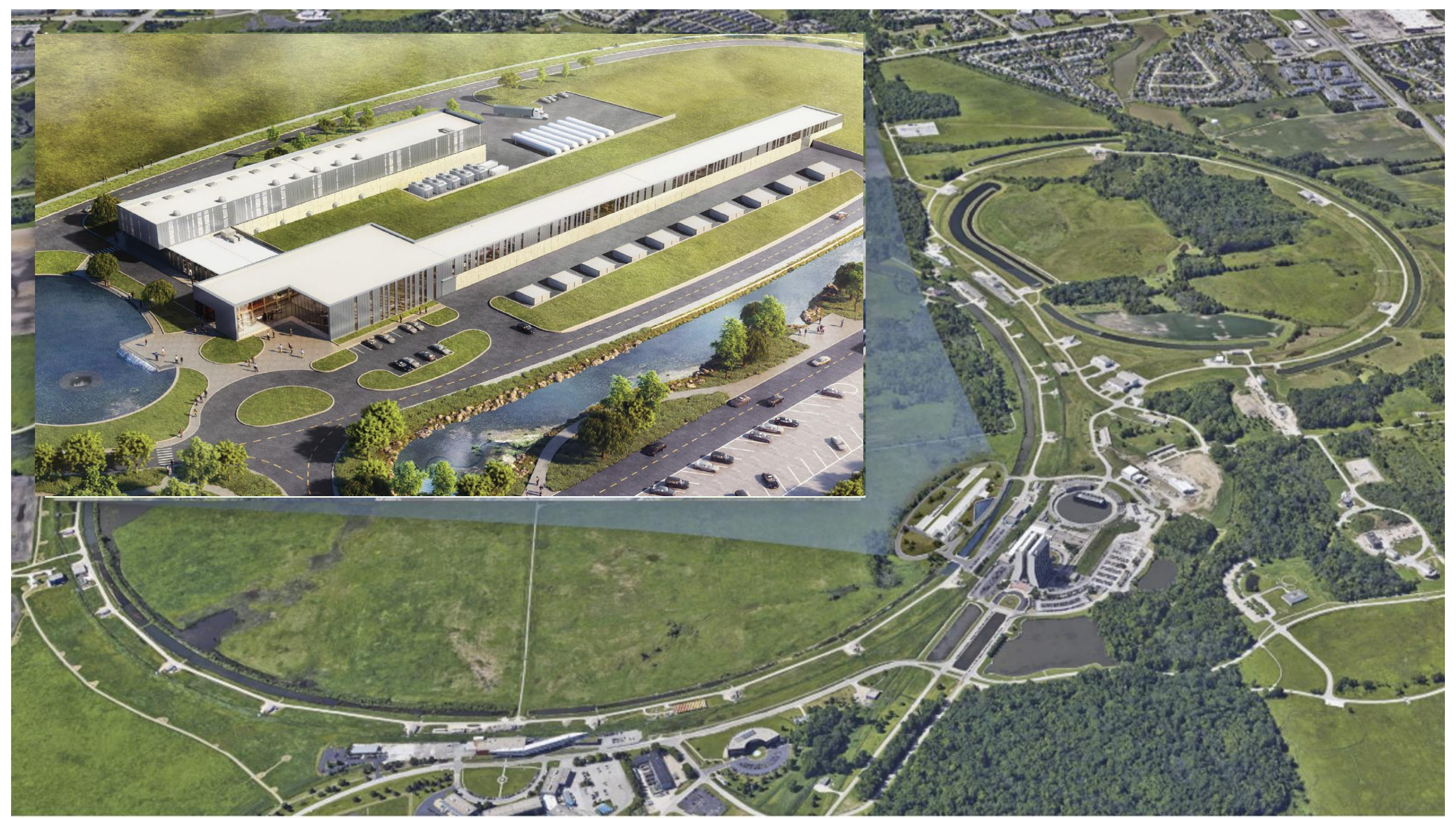




\section{PIP-II Site - Aerial View}

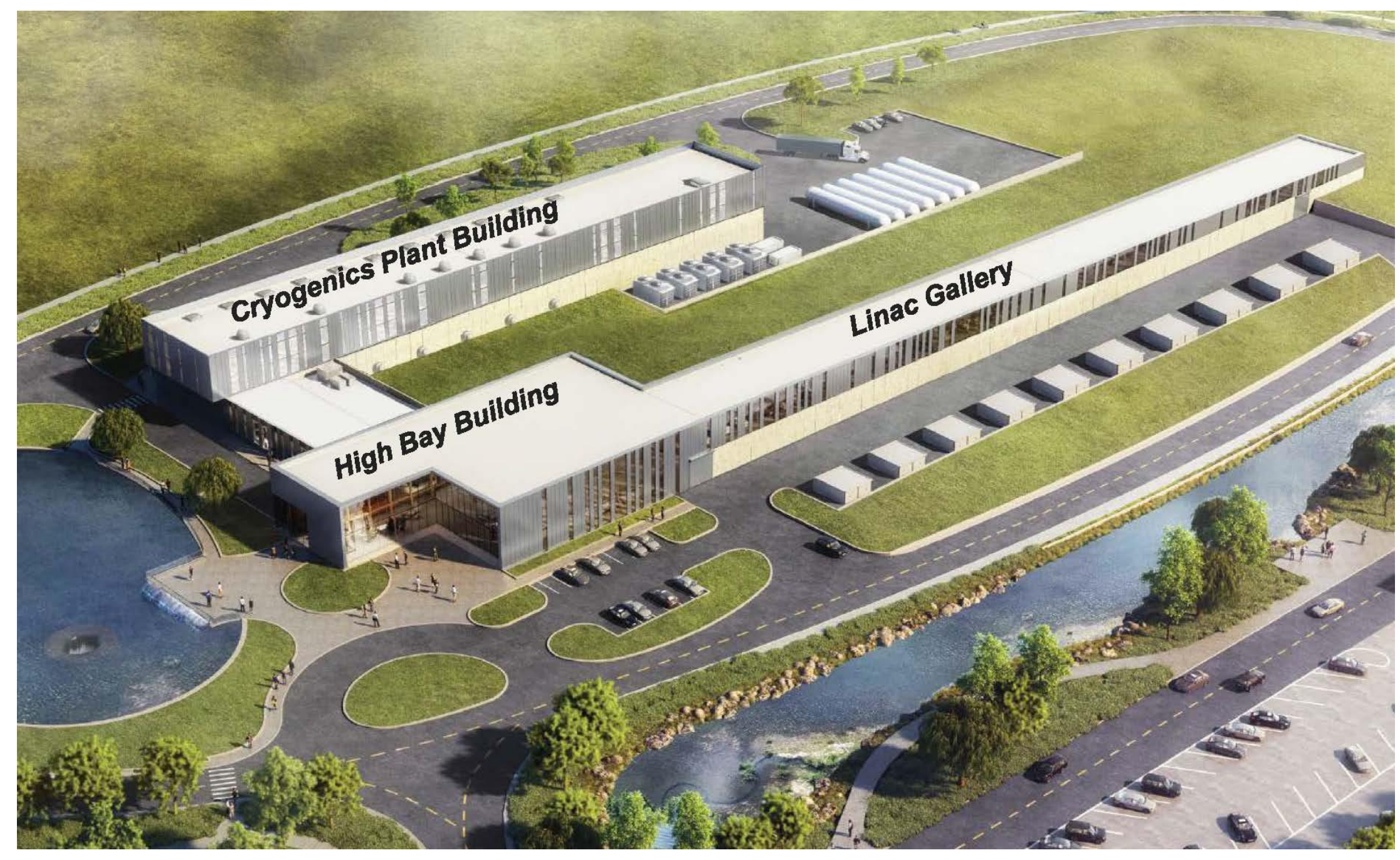




\section{The PIP-II 800 MeV Linac}

IS - LEBT - RFQ - MEBT

Room

Temperature Technology

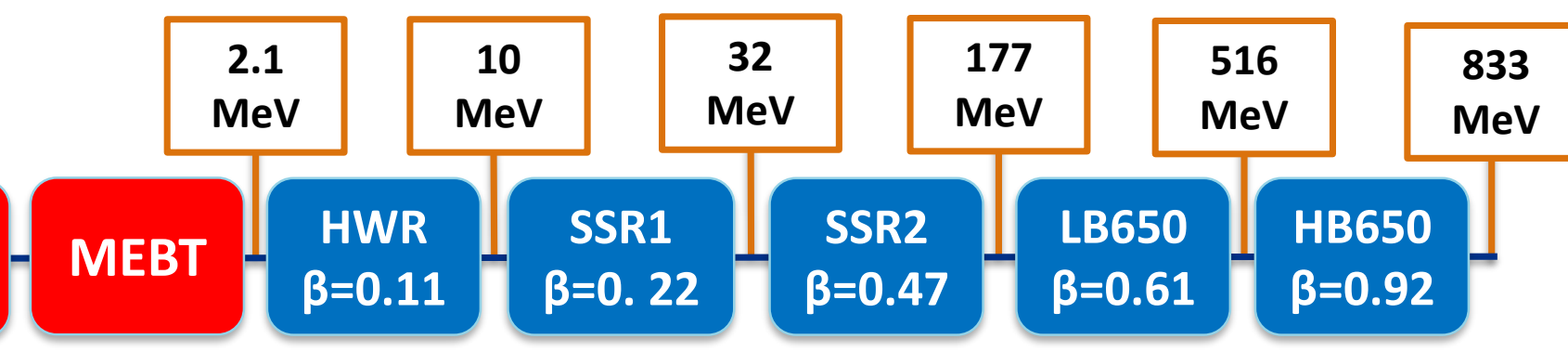

Superconducting Radio Frequency Technology

PIP-II Injector Test Facility (PIP2IT)

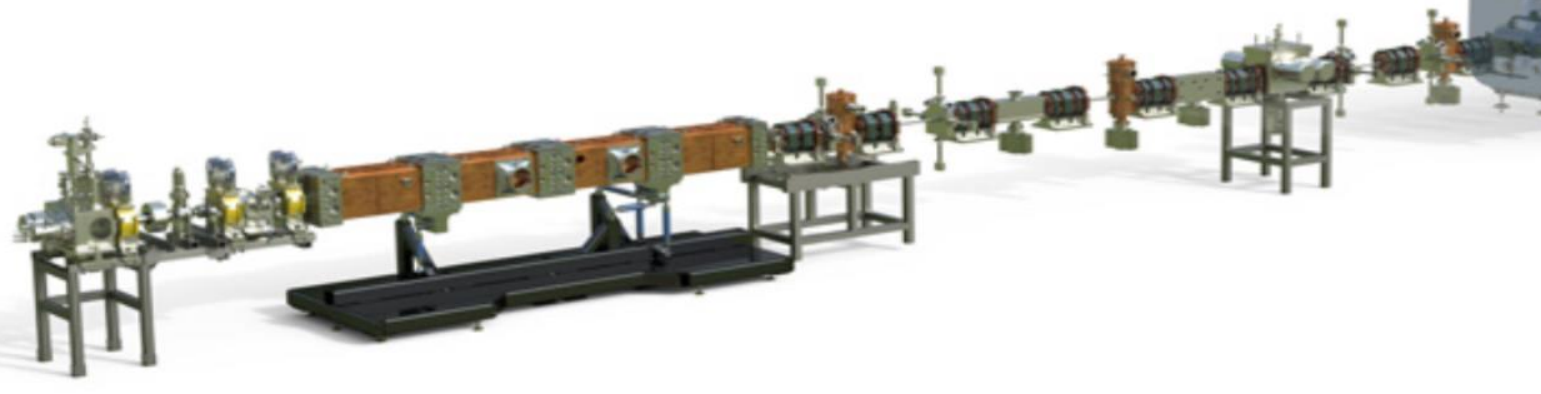

PIP-II Injector Test Facility retires a significant number of technical risks - complete in FY20 


\section{PIP-II Injector Test Facility (PIP2IT)}

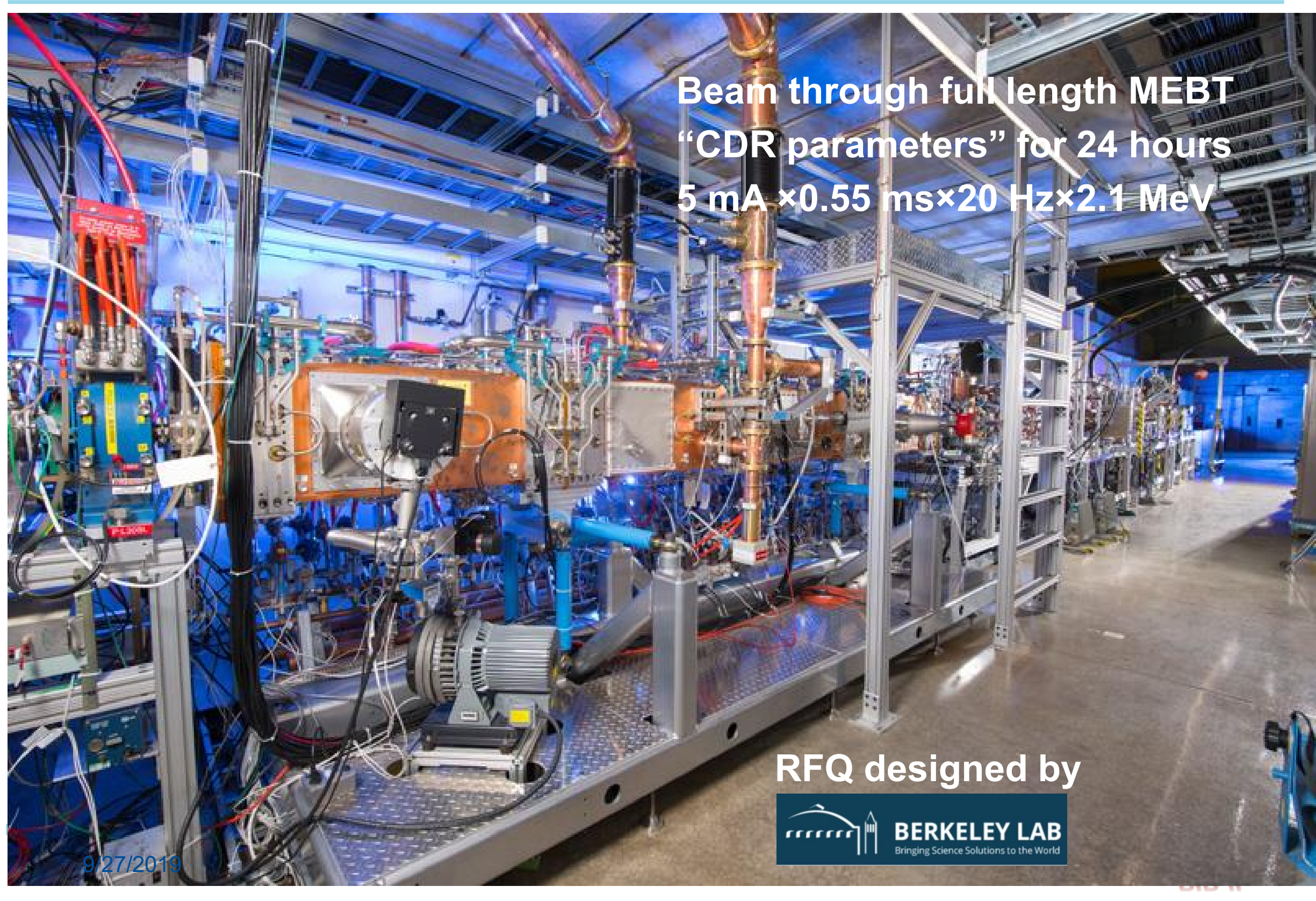




\section{PIP-II SRF Linac \& Areas of International Interest}

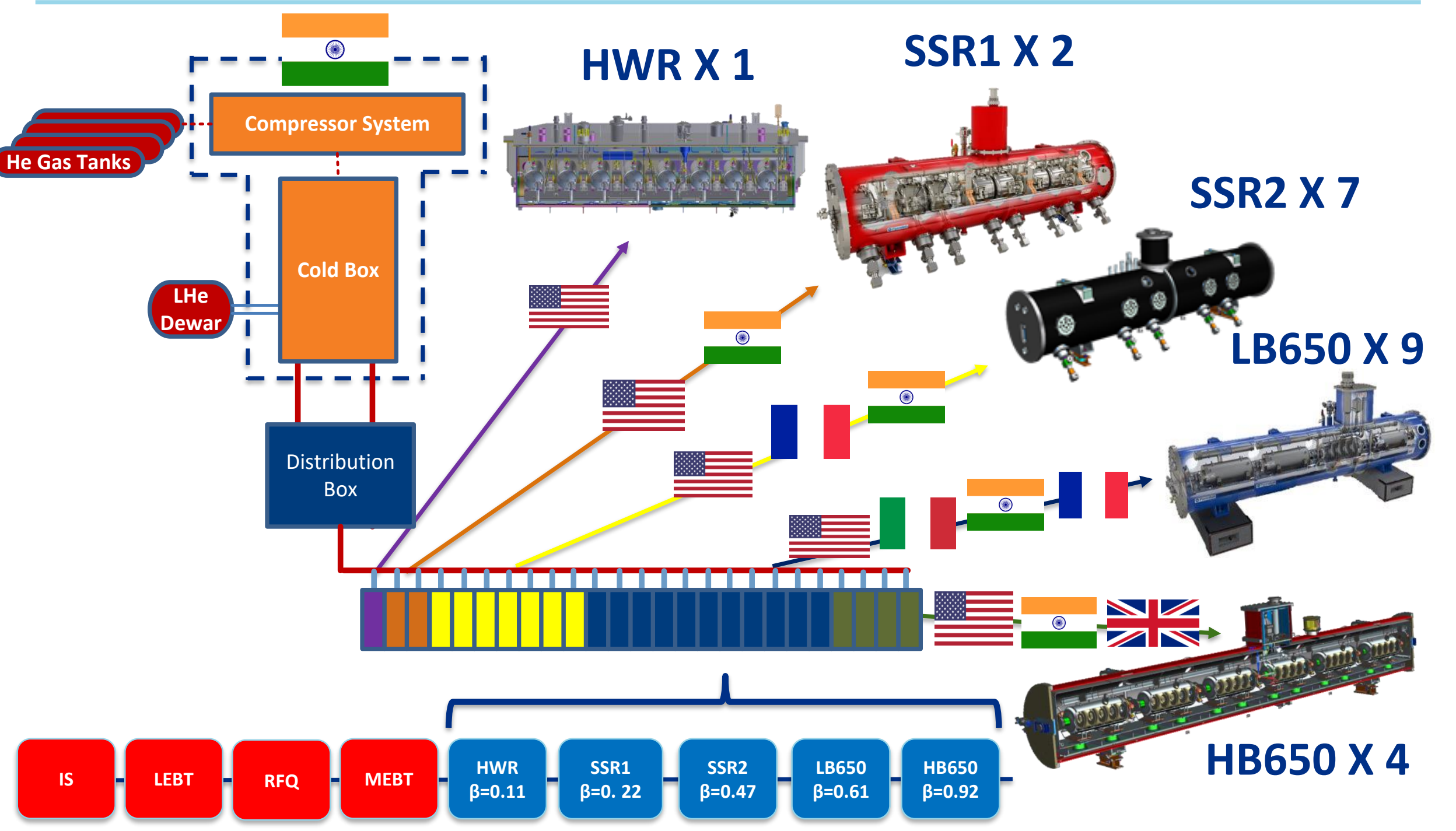

PIP-II is the first U.S. accelerator project to be built with major international contributions 
Half-Wave Resonator Cryomodule Fabrication by Argonne $A$

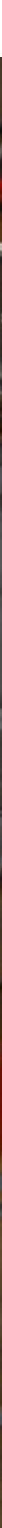

HWR cryomodule arrived at Fermilab 16-Aug-2019 


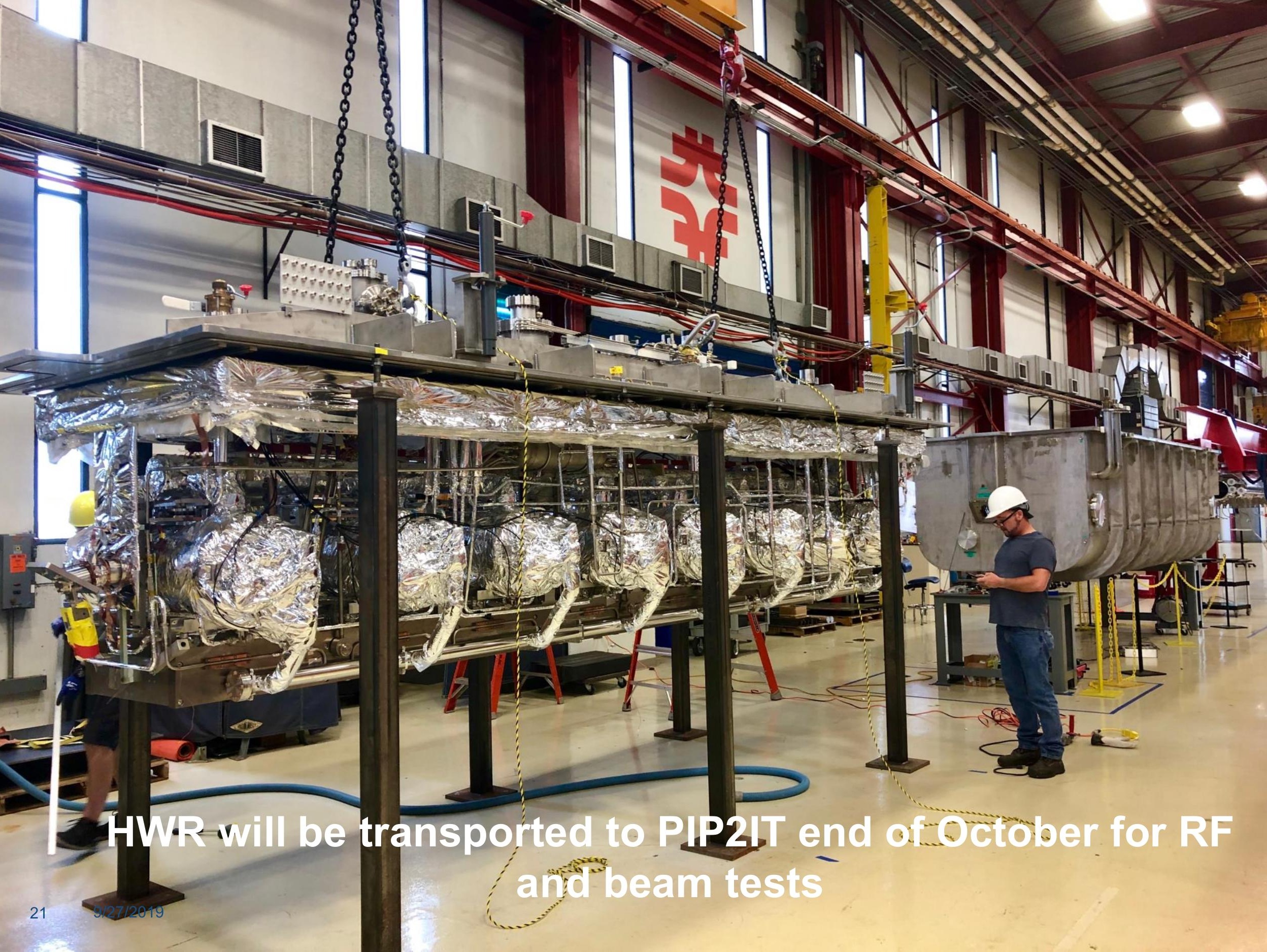




\section{SSR1 Assembly Netarly Complete -}

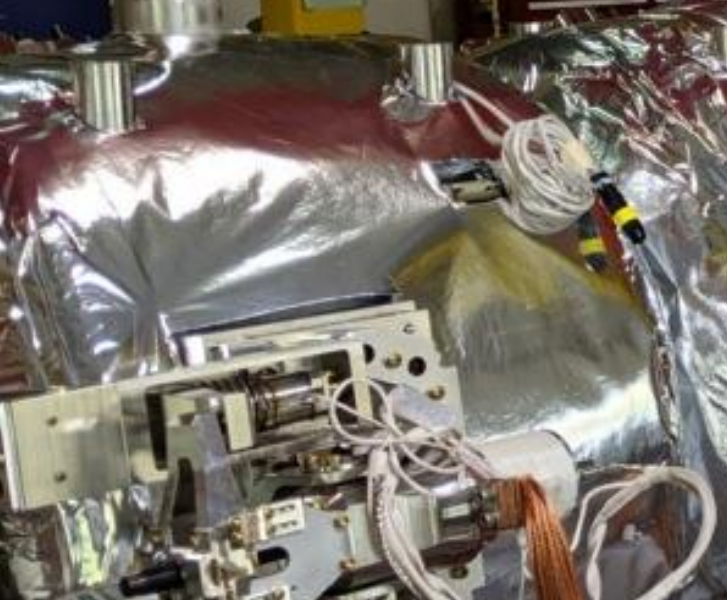

di)

11 a

Sting assembly complete - includes one cavity from DAE. Transport to PIP21T in November 2019

9/27/2019
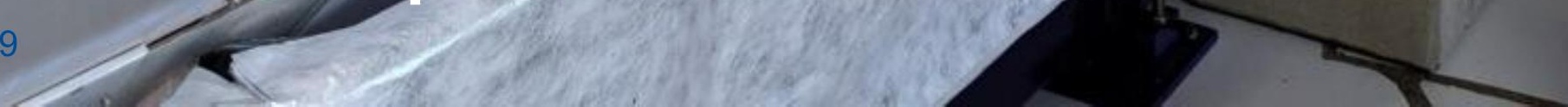


\section{SSR1 - Indian Cavity Performance}

STC* test with low power coupler

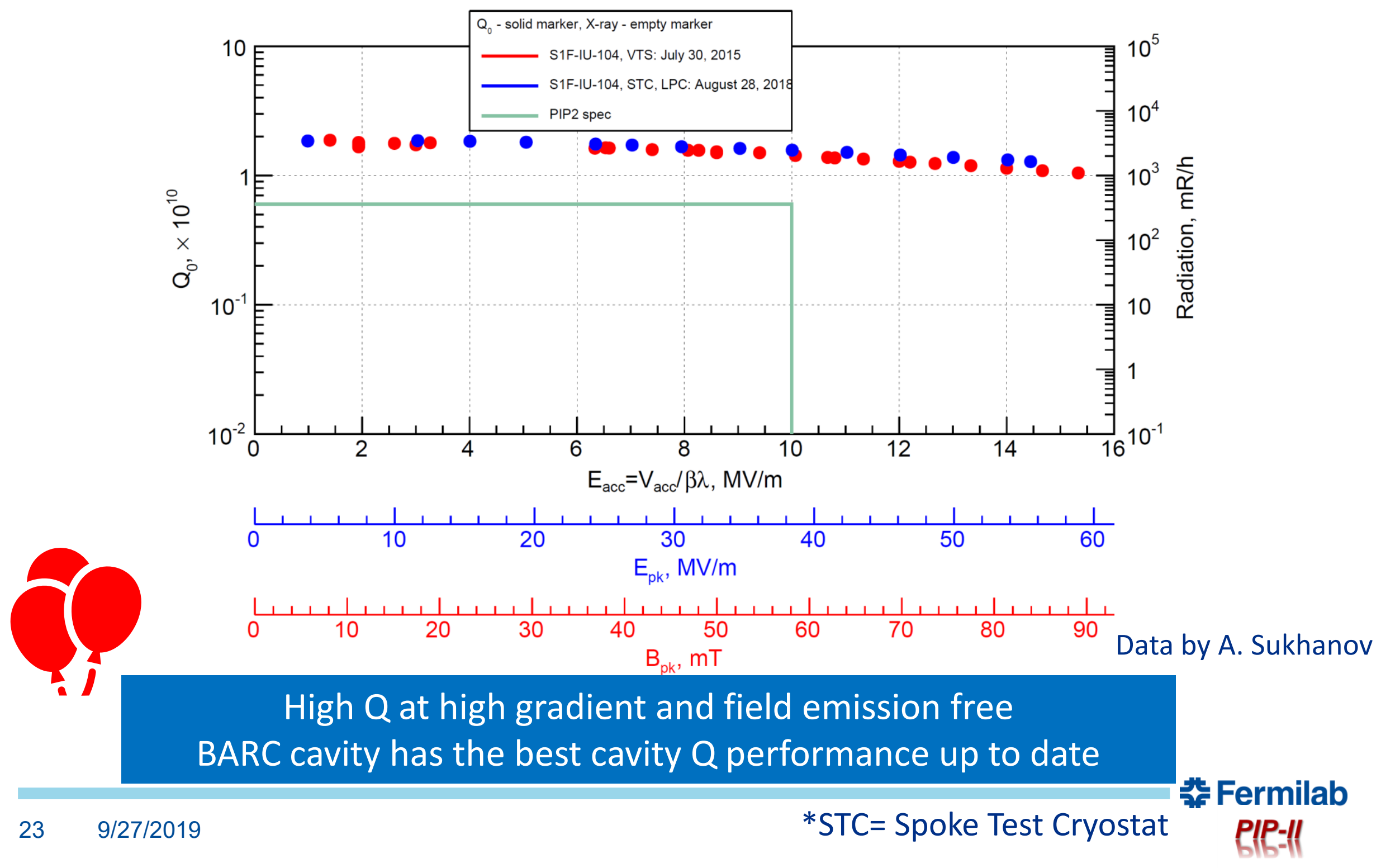




\section{SSR2}

- Cavity RF and mechanical design complete

- Nb ordered

- Prototype cavities expected in FY20

\section{LB650}
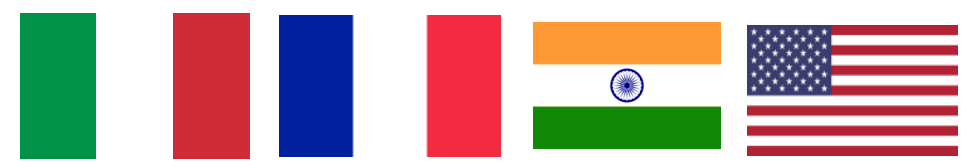

- Cavity RF and mechanical design complete

- Two prototype cavities will be delivered in 2019

\section{HB650}
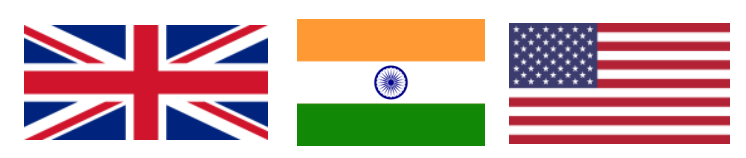

- First HB650 jacketed cavity

- HB650 high Q R\&D completed, design validation started

- Cryomodule design is in progress

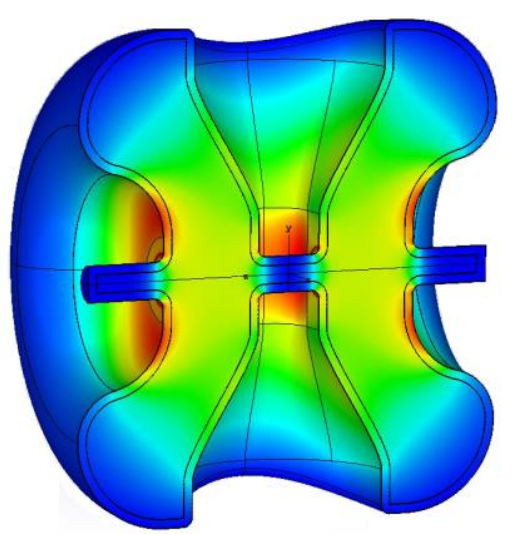

INFN 3D model of LB650 cavity
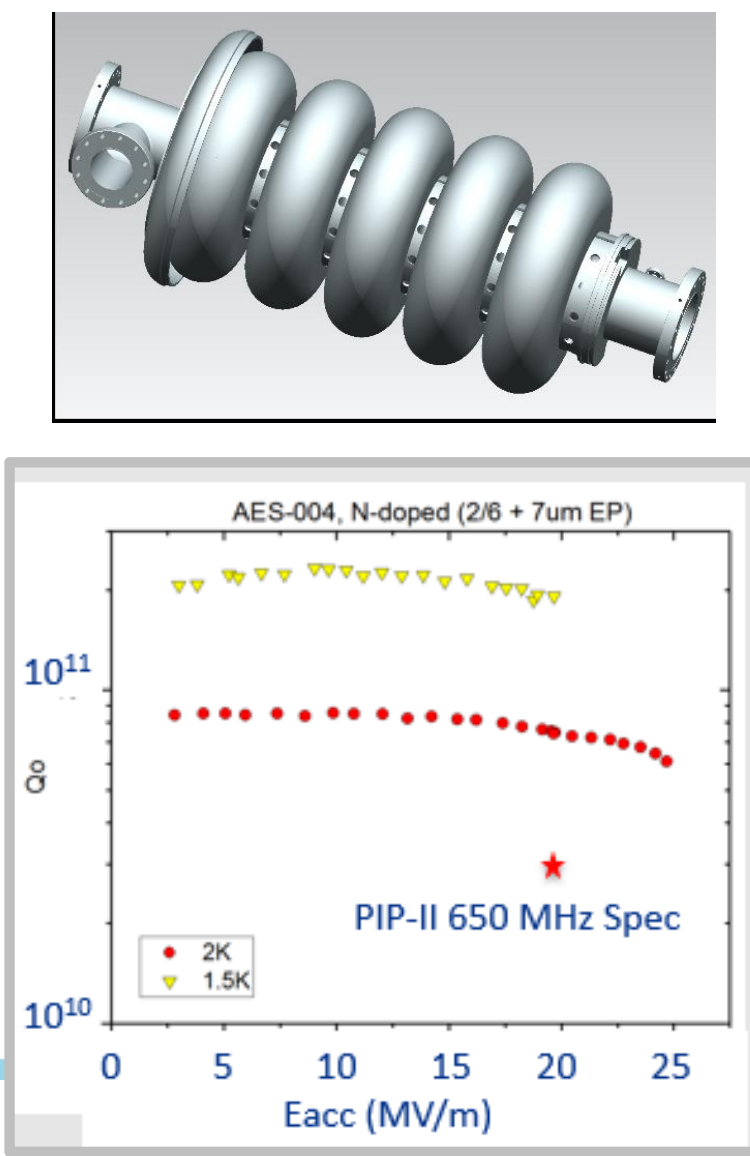


\section{R\&D Challenges in SRF}

- High $Q_{0}$ and High Gradient $\rightarrow 3 \times 10^{10}$ and $20 \mathrm{MV} / \mathrm{m}$

- Nitrogen-doping evolved from discovery to proven technology for LCLS-II

- Tests at $650 \mathrm{MHz}$ show that an additional doping optimization is desirable (relative to doping developed for $1.3 \mathrm{GHz}$ )

- Suppression of Microphonics

- Maximum detuning $<20 \mathrm{~Hz}(\sigma<3 \mathrm{~Hz})$

- Passive means

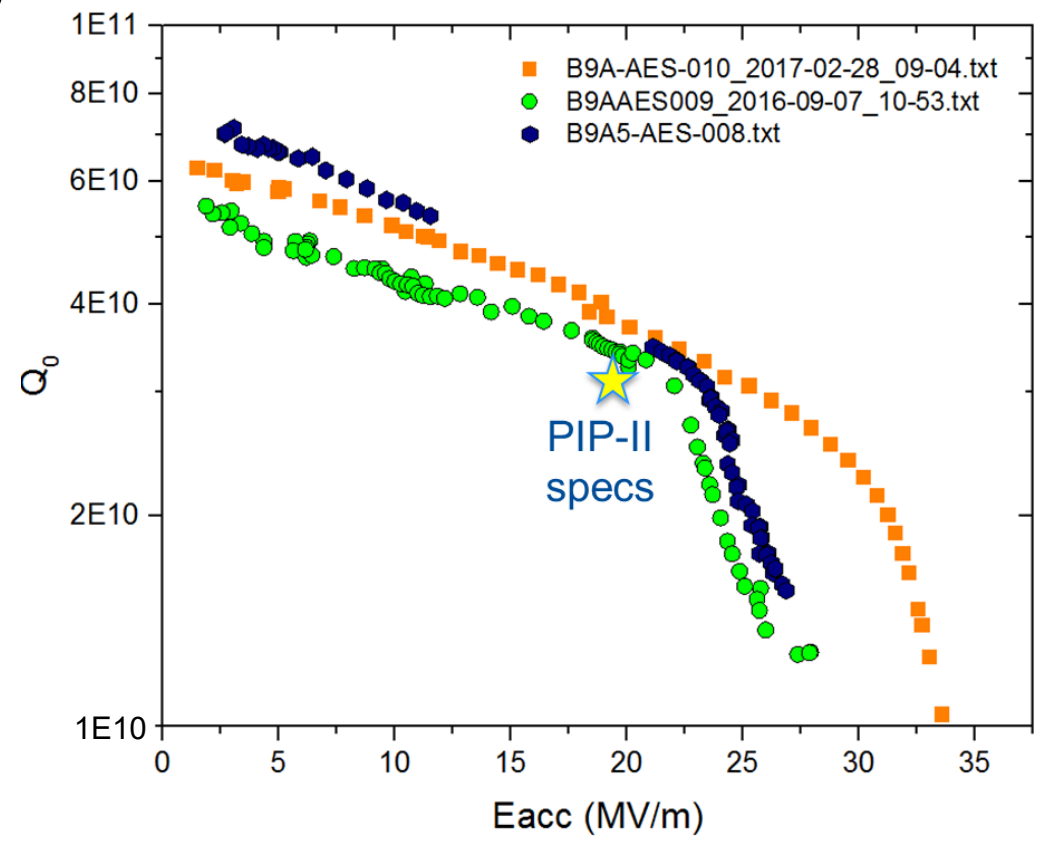

- Cryomodule design

- Active means

Vertical test results for 5-cell HB cavity

- Adaptive Detuning Control Algorithm 


\section{Linac Installation \& Commissioning: PIP2IT}

- Nearly full scale PIP-II 2.1 MeV normal conducting front-end

- Support HWR and SSR1 CM commissioning with beam

- After FY20 will be repurposed to PIP-II CM test facility

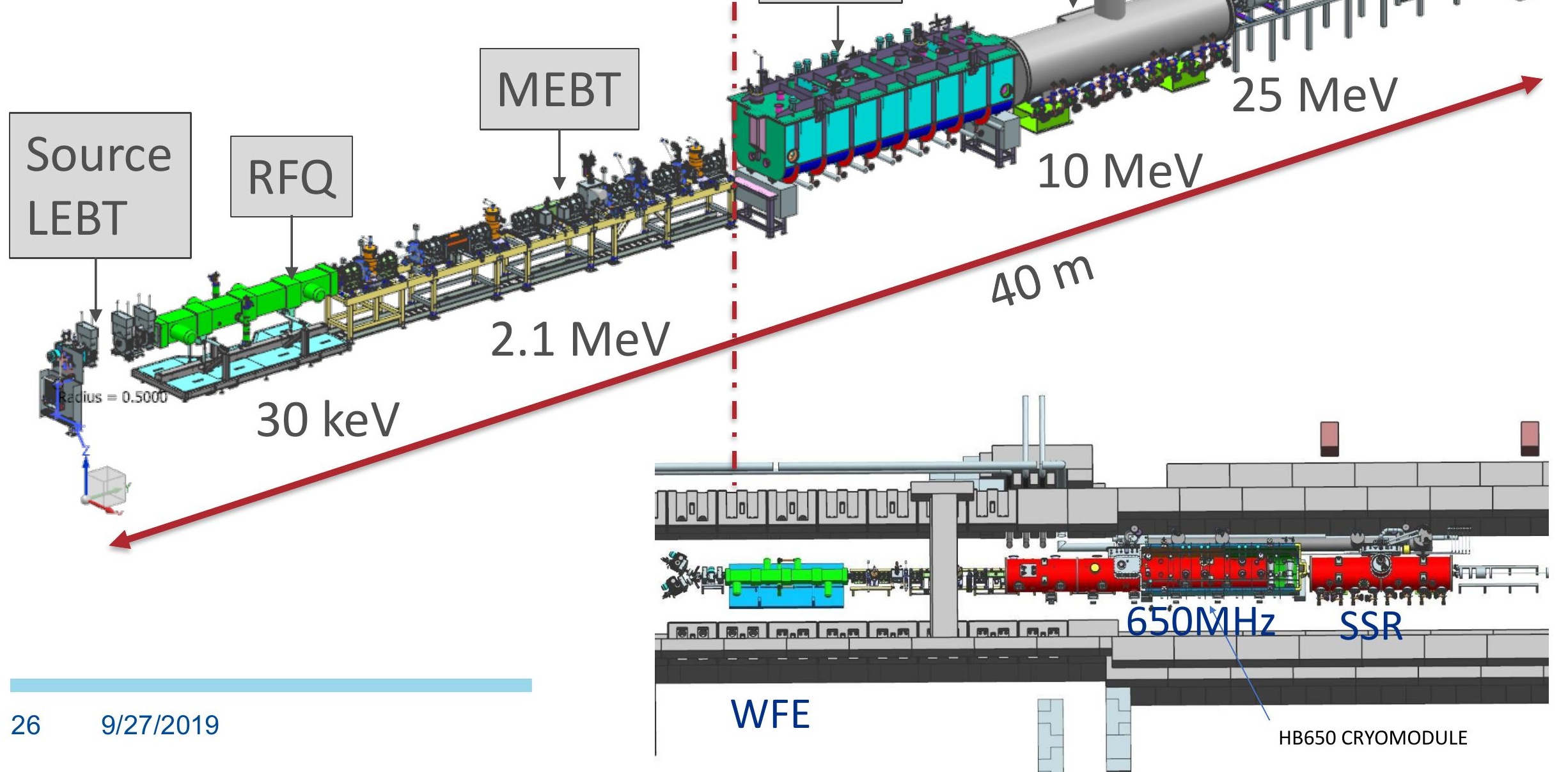




\section{Fermilab's Path to 1.2 MW on LBNF Target}

- Increase the number of protons per Booster pulse from $4.3 \mathrm{e} 12$ (present) to $6.5 \mathrm{e} 12$

- Increase of Booster rep. rate from $15 \mathrm{~Hz}$ to $20 \mathrm{~Hz}$

- Reduce Main Injector cycle from $1.33 \mathrm{~s}$ to $1.2 \mathrm{~s}$

Increases in Booster injection energy, pulse intensity and repetition rate require upgrades to Booster, Recycler Ring (RR), and Main Injector (MI).

Collaboration with J-PARC experts critical to successful upgrade of Fermilab synchrotrons 


\section{Accelerator Complex Upgrades}

- Upgrades to Booster, Recycler, and Main Injector (MI) required to accommodate:

- increased injection energy (400 MeV to $800 \mathrm{MeV}$ )

- increased intensity (4.3E12 to 6.5E12 Booster, $5 \mathrm{E} 13$ to $7.5 \mathrm{E} 13 \mathrm{MI})$

- higher repetition rate $(15 \mathrm{~Hz}$ to $20 \mathrm{~Hz})$

- Scope of Ring upgrades:

- New Booster Injection girder

- New 53 MHz Recycler cavities

- Upgraded Main Injector RF Cavities

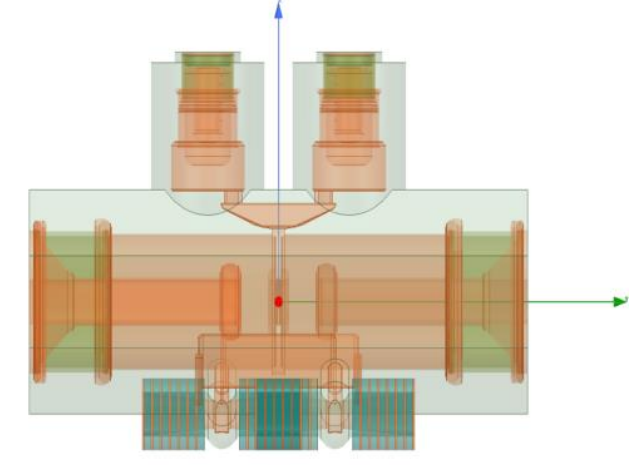

MI Cavity Model with two PAs

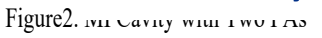

- New beam line from the superconducting Linac to the Booster, new beam absorber line and beam dump 


\section{PIP-II Groundbreaking - 15 March 2019}

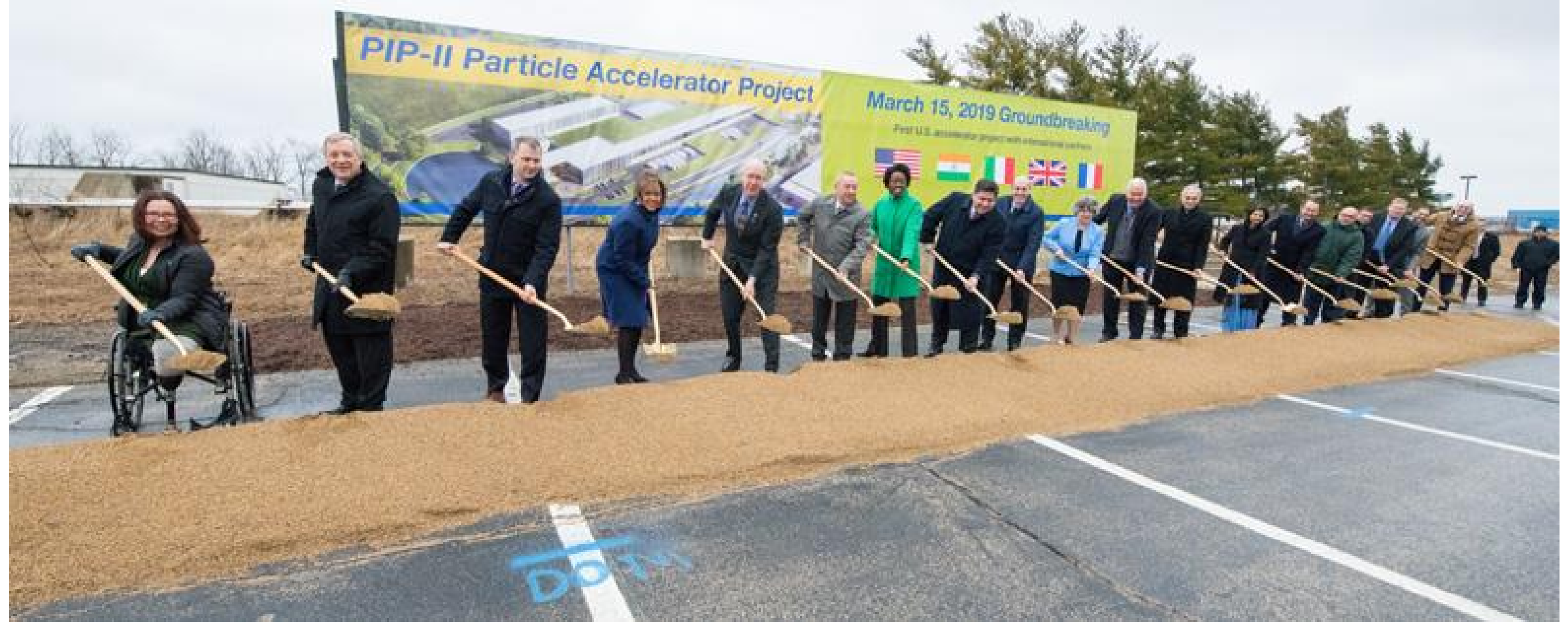




\section{Conventional Facilities}

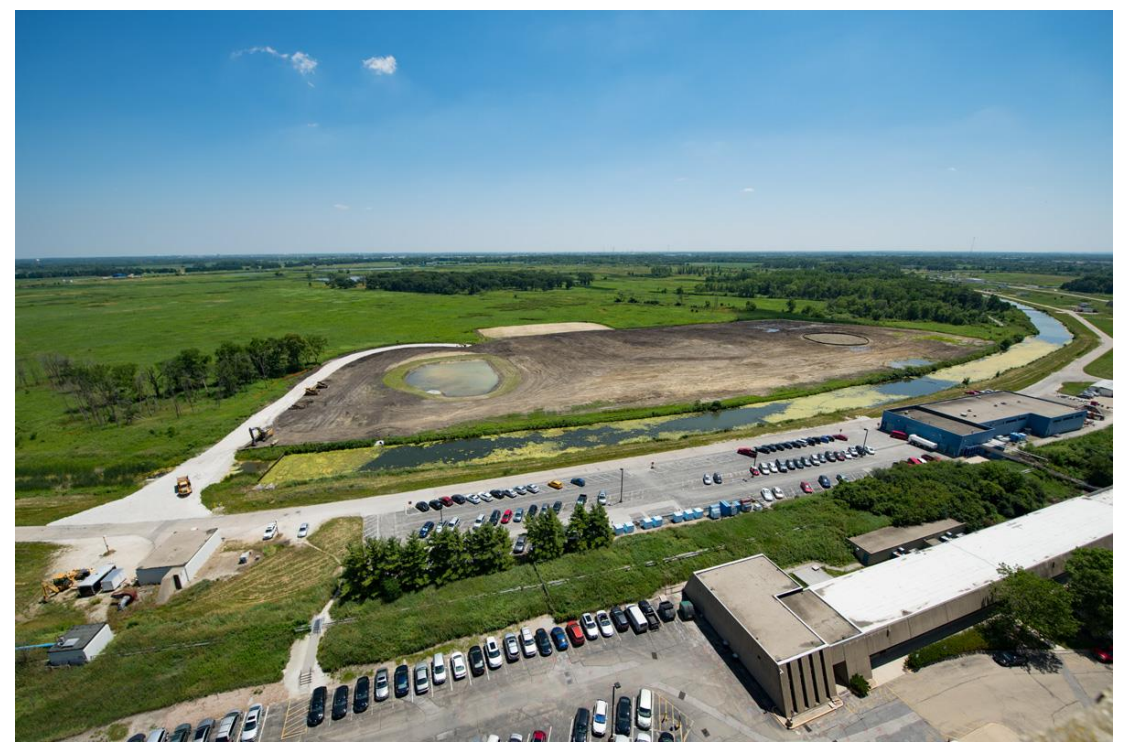

\section{Site Clearing Complete} Under special authorization prior to CD-2/3a granted by DOE

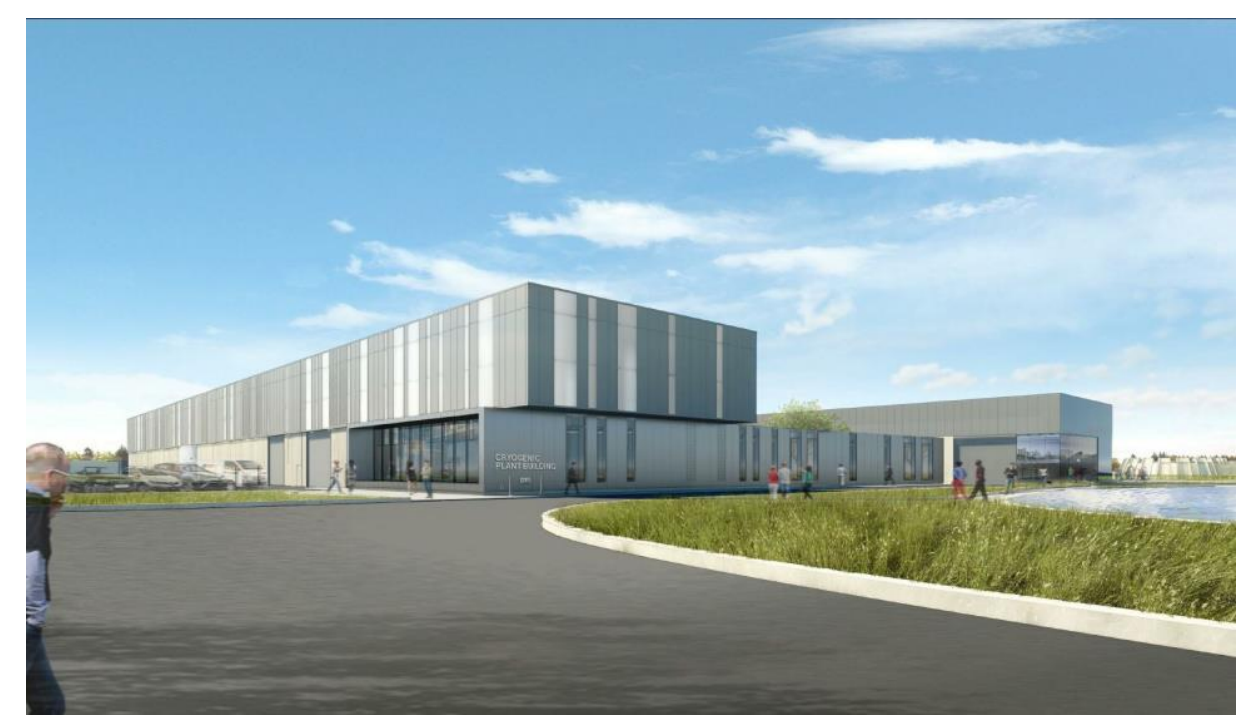

Cryogenics Plant Building Design Complete; Ready for Procurement

\section{Linac Complex}

Conceptual Design update underway, scheduled for completion in November 2019. Will form the basis of final design 


\section{Schedule Overview}

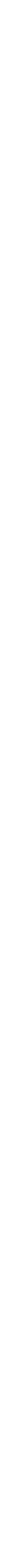

Planned

Project

Complete

arly CD-4) 


\section{PIP-II \\ International Partnerships}

莫 Fermilab 


\section{PIP-II International Partnership Principles}

- Pursue partnerships where broader interests are aligned, specifically technology (SRF) and science (DUNE)

- Bring international institutions in early as Partners

- Share project planning, R\&D to provide joint sense of ownership

- Integrate Partners in PIP-II project management principles

- Establish a multi-layered governance structure (INC, P2LDC, P2PEB ${ }^{*}$ )

- Establish International Agreements

*International Neutrino Council; PIP-II Laboratory Directors Council;

PIP-II Project Executive Board 


\section{PIP-II International Partners, Expertise and Capabilities}

India, Department of Atomic Energy (DAE) (started 2009) BARC, RRCAT, VECC; also IUAC

Substantial engineering/manufacturing experience Superconducting correction magnets for LHC

Construction \& operation of $2 \mathrm{GeV}$ synch light source @ RRCAT

\section{Italy, INFN (started 2016)}

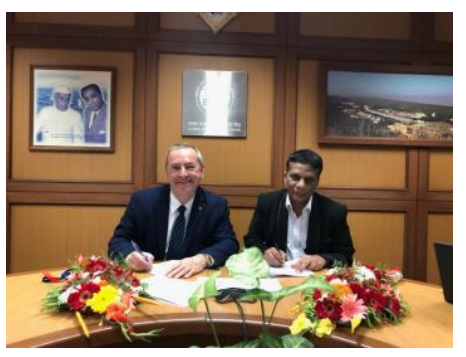

Internationally recognized leader in superconducting RF technologies

SRF cavity and cryomodule (CM) fabrication for XFEL SRF cavity fabrication for ESS

$\mathbf{N Z / L}$

\section{UK, UKRI (started 2017)}

Substantial engineering and manufacturing experience

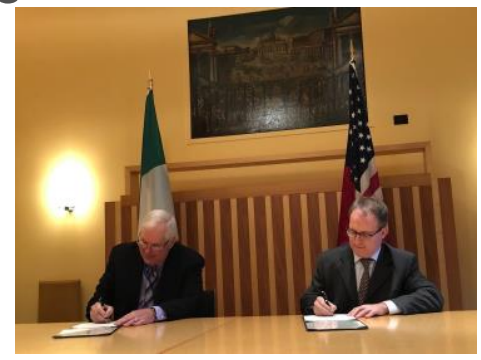

Construction and operation of domestic synchrotron light \& neutron sources

SRF cavity processing and testing for ESS

France, CEA, CNRS/IN2P3 (started 2017)

Internationally recognized leader in large-scale CM assembly

CM assembly for European XFEL and ESS

SSR2 cavities and couplers for ESS

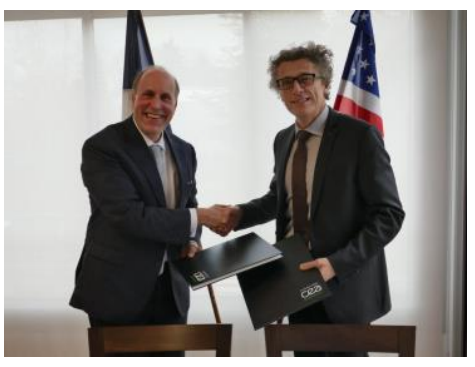

PIP-II Project benefits from world-leading expertise, facilities.

"Timing is perfect" 


\section{Major In-Kind Contribution Production Deliverables}

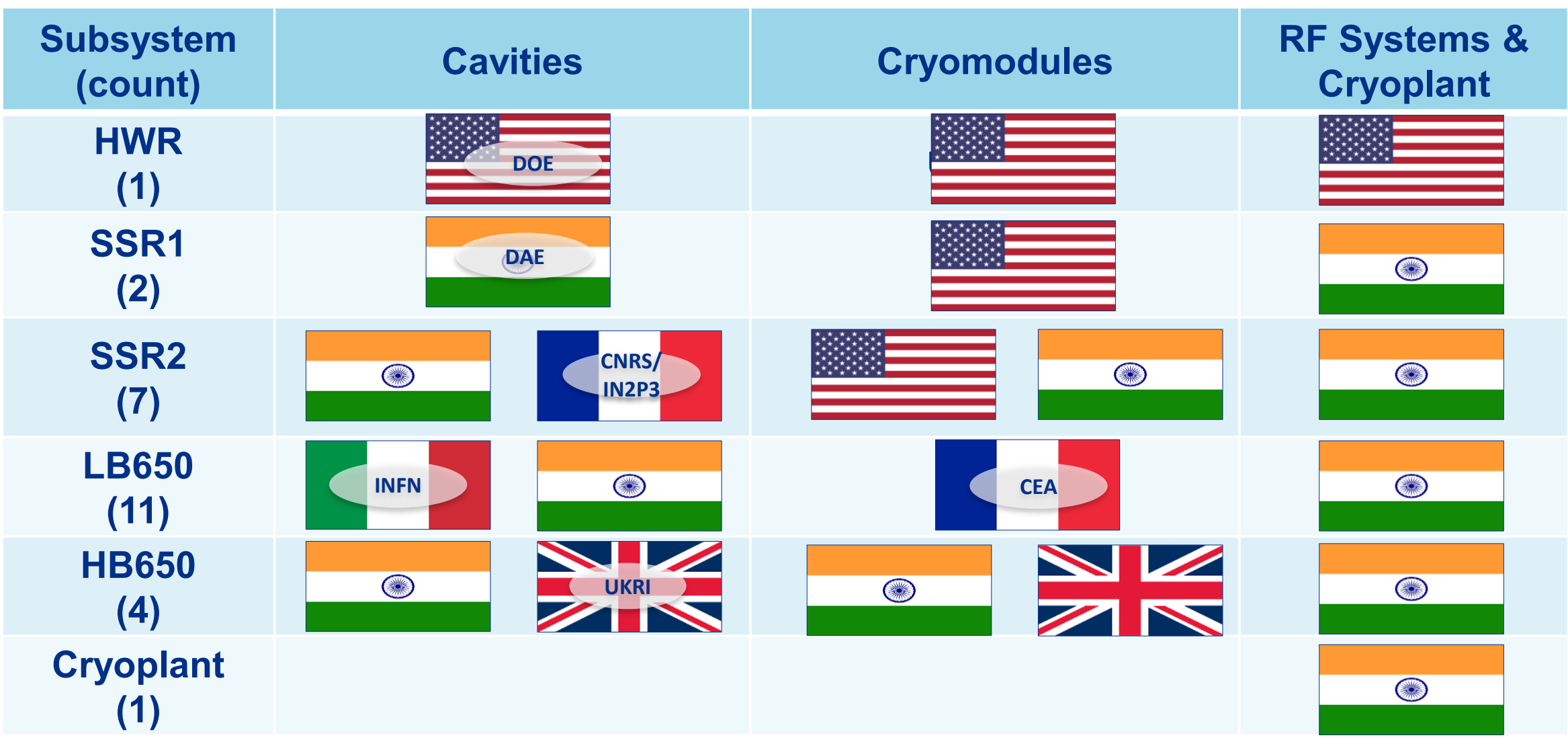

International partnerships are essential for the success of the PIP-II Project 
First PIP-II Project Executive Board Meeting - 3/14/2019

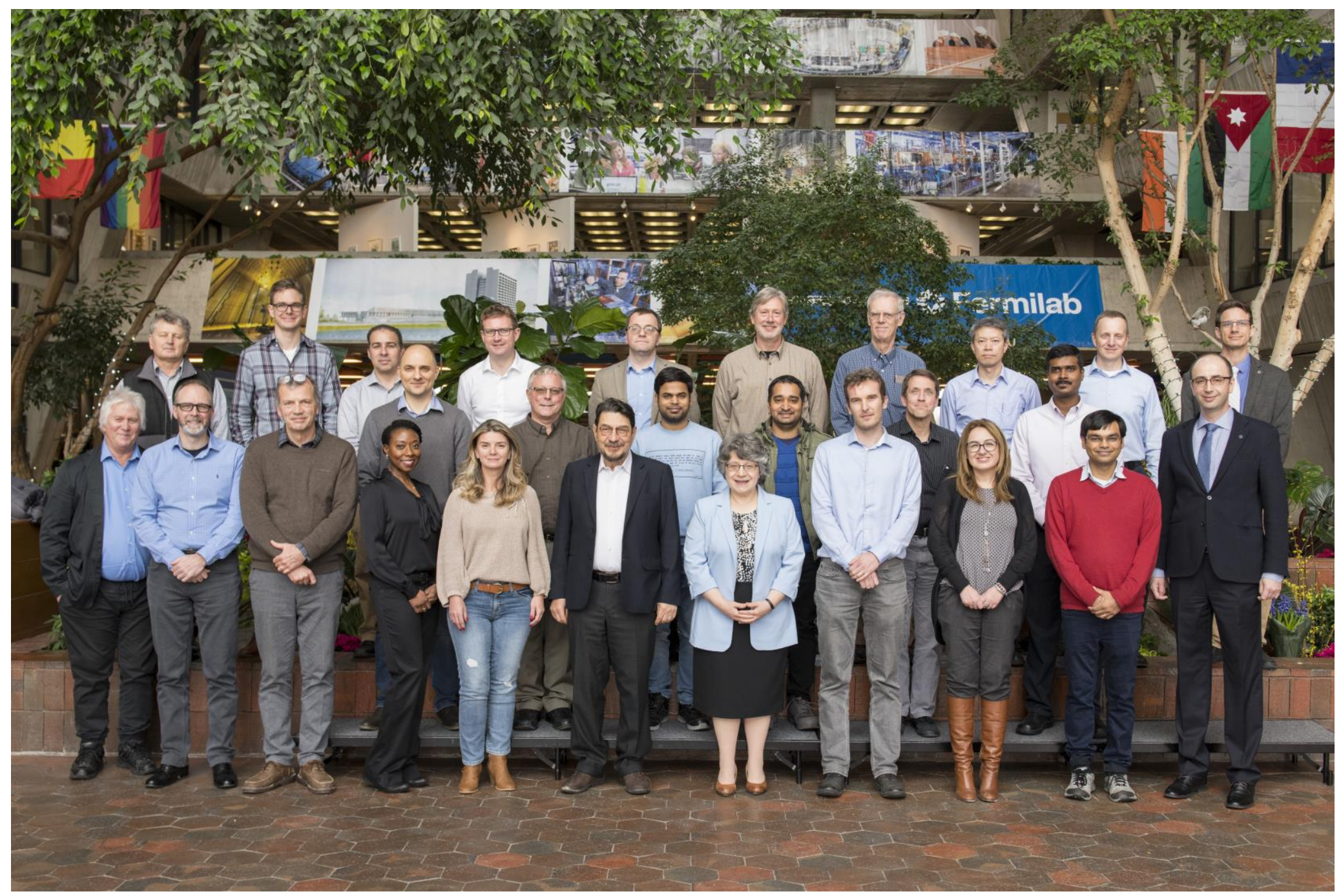

Next Board meeting at IPNO, Orsay on October 11, 2019 


\section{Summary}

- PIP-II is breaking new ground

- First DOE accelerator to be built with significant international contributions

- Highest energy CW SRF proton linac

- PIP-II is the "heart and soul" of Fermilab, and critical to the success of the international neutrino program

- Baseline review is scheduled Jan 2020

- Our world-leading international Partners enable DOE/Fermilab to build a highly capable machine at reduced cost to DOE

- We greatly appreciate the enduring support from DOE and international Partners, and their commitment to our joint success and furthering neutrino science 


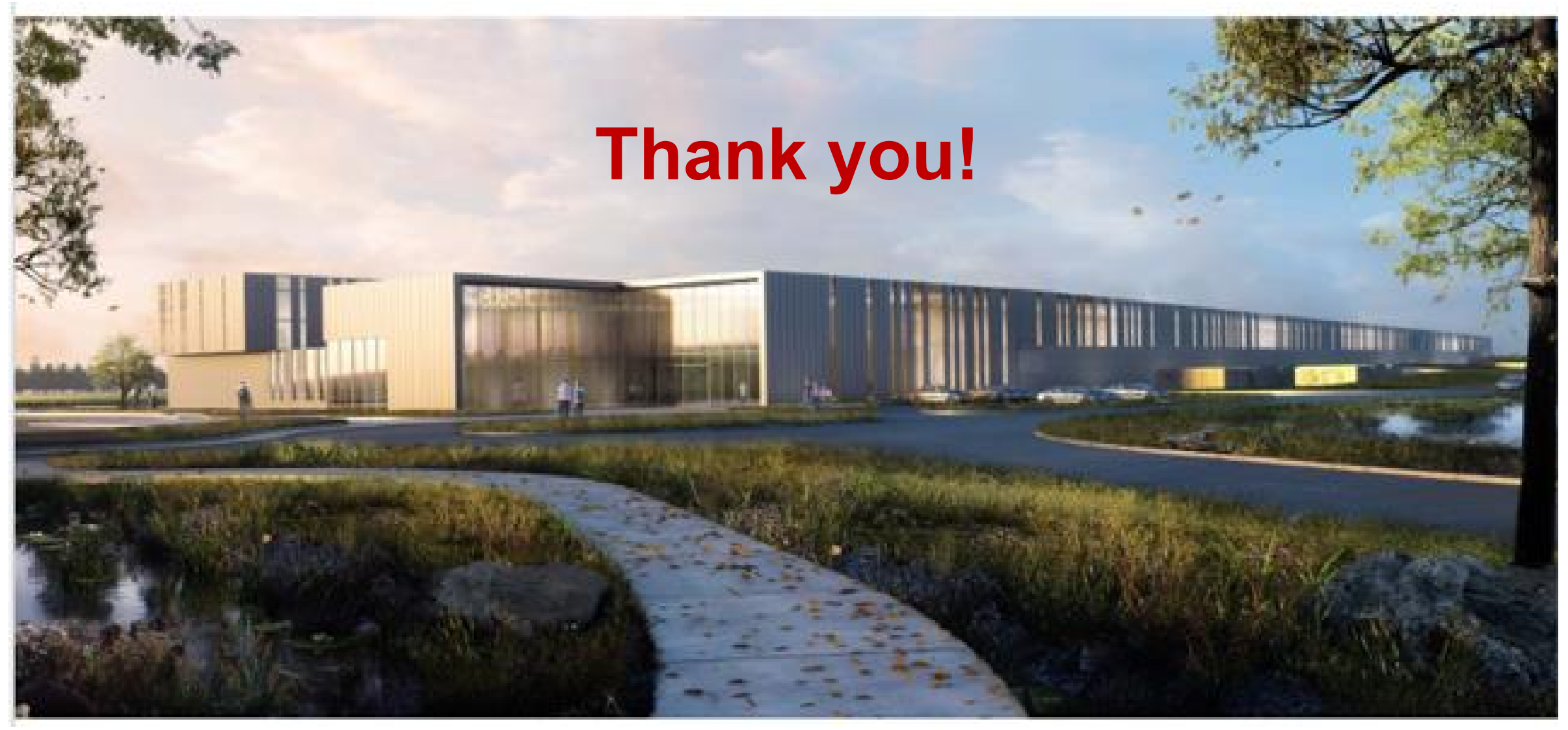




\section{PIP-II Project Key Performance Parameters}

\begin{tabular}{|c|c|c|c|}
\hline \# & Description & Threshold KPP & Objective KPP \\
\hline 1 & & & Accelerate $\mathrm{H}$ - beam to $700 \mathrm{MeV}$. \\
\hline & $\begin{array}{l}\text { Linac Beam } \\
\text { Energy }\end{array}$ & Accelerate $\mathrm{H}$ - beam to $600 \mathrm{MeV}$ & $\begin{array}{l}\text { Linac systems required to } \\
\text { accelerate beam to } 800 \mathrm{MeV} \\
\text { installed and tested. }\end{array}$ \\
\hline 2 & $\begin{array}{l}\text { Linac Beam } \\
\text { Intensity }\end{array}$ & $\begin{array}{l}\mathrm{H} \text { - beam delivered to beam } \\
\text { absorber at the end of the linac }\end{array}$ & $\begin{array}{l}\mathrm{H} \text { - beam with an intensity of } \\
1.3 \times 10^{12} \text { particles per pulse at a } \\
20 \mathrm{~Hz} \text { repetition rate delivered to } \\
\text { Beam Transfer Line beam absorber }\end{array}$ \\
\hline 3 & $\begin{array}{l}\text { Booster, } \\
\text { Recycler, } \\
\text { Main Injector } \\
\text { Upgrades }\end{array}$ & $\begin{array}{l}\text { Booster, Recycler, Main Injector } \\
\text { upgrades required to support } \\
\text { delivery of } 1.2 \mathrm{MW} \text { onto the } \\
\text { LBNF target are installed and } \\
\text { tested without beam }\end{array}$ & $\begin{array}{l}\text { Linac beam injected and circulated } \\
\text { in Booster }\end{array}$ \\
\hline & & \multicolumn{2}{|c|}{$\begin{array}{l}\text { Design Parameters } \\
\text { Beam energy: to } 800 \mathrm{MeV} \\
\text { Linac beam intensity: } 6.7 \mathrm{E} 12 \text { particles per pulse at } 20 \mathrm{~Hz} \\
\text { Proton beam power delivered on LBNF target: } 1.2 \mathrm{MW}\end{array}$} \\
\hline
\end{tabular}




\section{Warm Front End}

- $15 \mathrm{~mA}, 30 \mathrm{kV}$ ion source

- 2 m LEBT ('slow' chopper, dif. pumping, envelope match to RFQ)

- $\quad 2.1 \mathrm{MeV}, 162.5 \mathrm{MHz}$ RFQ

- 14 m MEBT (bunch-by-bunch chopper, shielding wall, envelope match)

- Successful integration of magnets from DAE/BARC.
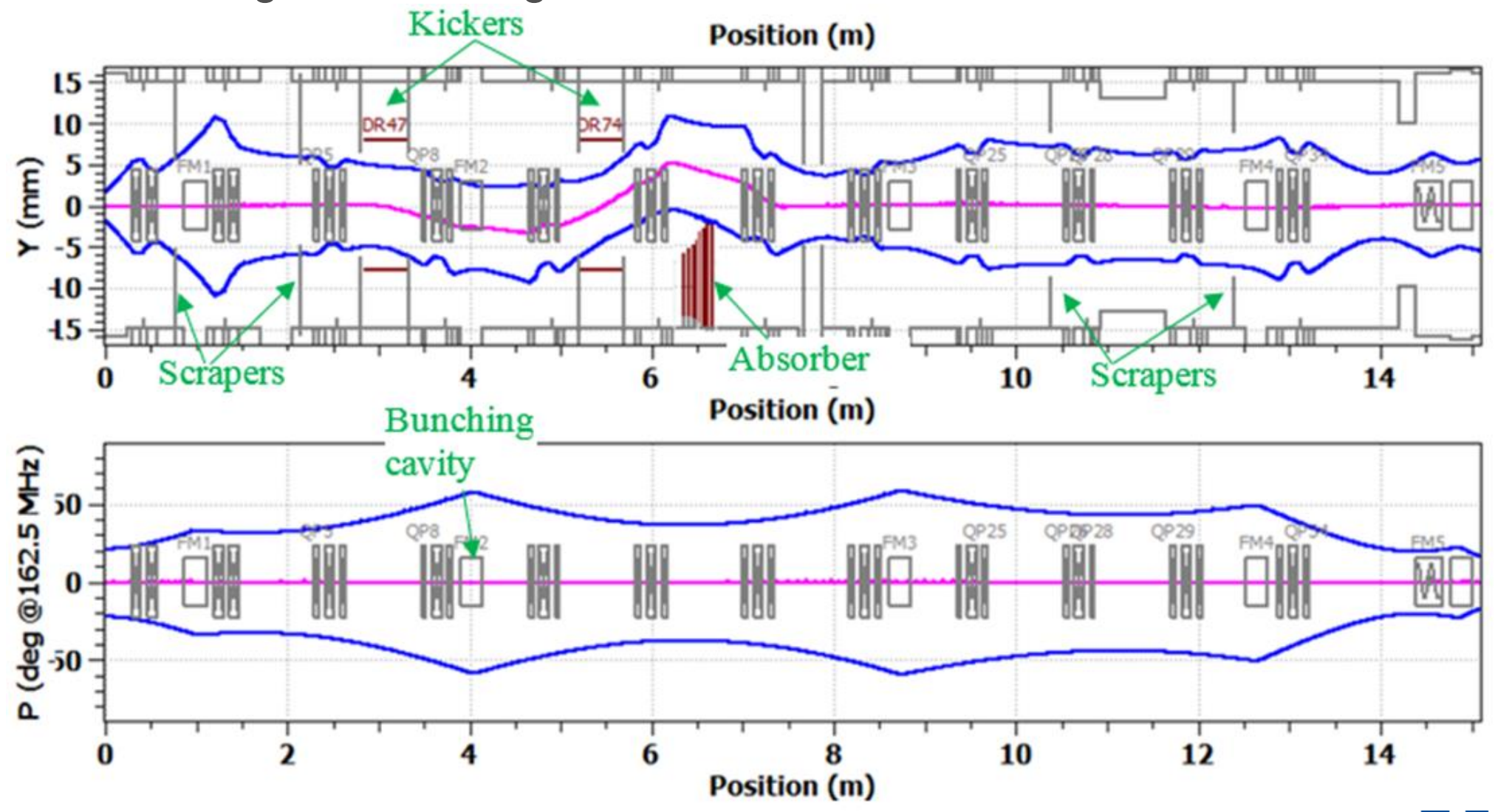


\section{LBNF: From Illinois to a mile underground in South Dakota}

\section{Illinois:}

- World's most powerful and advanced neutrino beam

- DUNE "near" detector
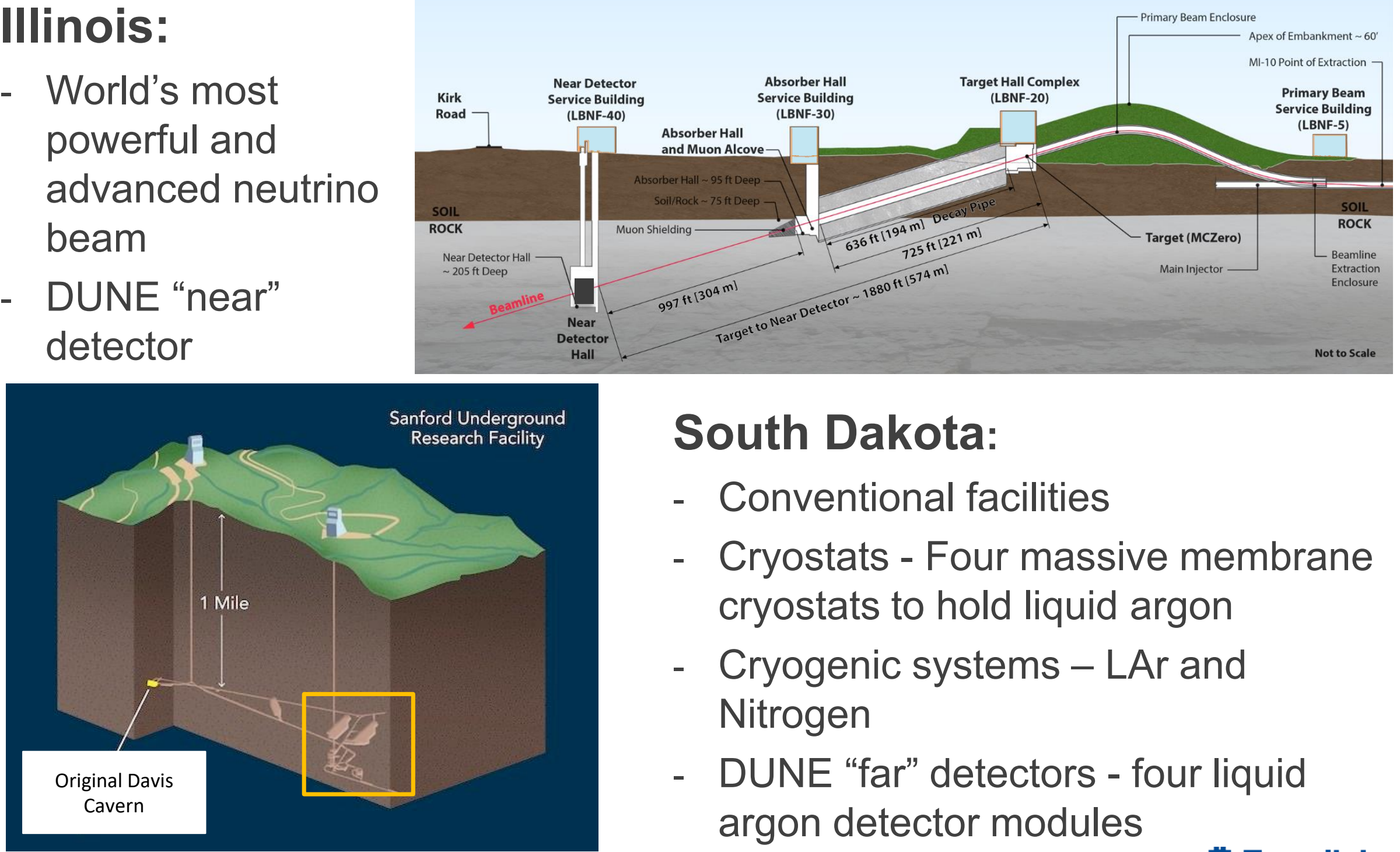

\section{South Dakota:}

- Conventional facilities

- Cryostats - Four massive membrane cryostats to hold liquid argon

- Cryogenic systems - LAr and Nitrogen

- DUNE "far" detectors - four liquid argon detector modules 


\section{Cryomodule (CM) Development Path}

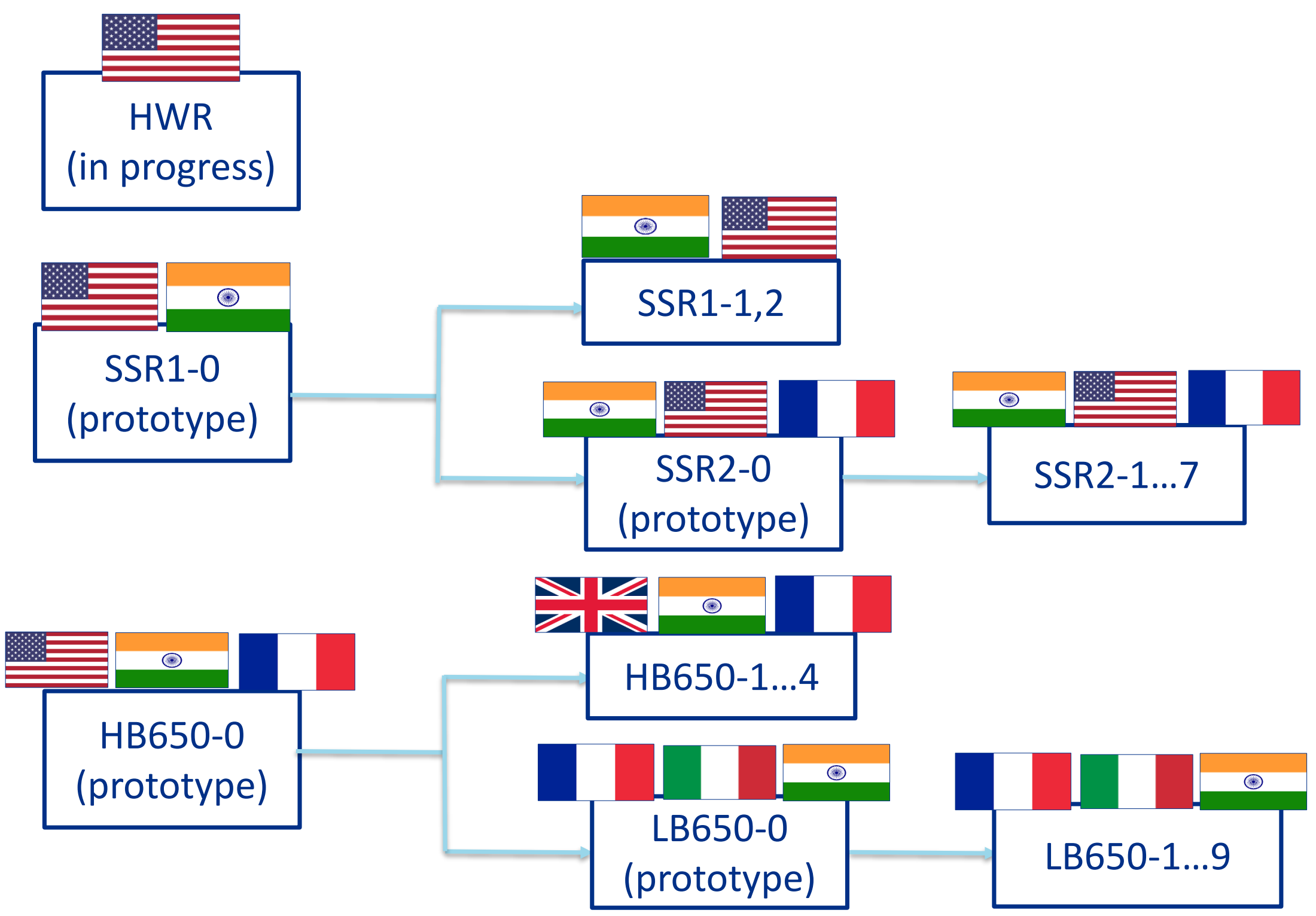

SRF plan includes four prototype CMs to retire or mitigate major technical risks, including transportation 